\title{
Organizational Power Politics and Leadership Experiences on the View and Use of Power in Organizations
}

\author{
Remi Alapo \\ University of Phoenix, Arizona, USA
}

\begin{abstract}
Organizational power politics permeates all actions within an organization. Power is one person's ability to exert change on another person's way of life and actions. Using power is a valuable means to influence and achieve intended desires and future action in others. Power is instrumental; it's a means to achieve goals other than the attainment of power itself. Power may also be expressed as one person's dependence on another. Power can, and sometimes is, a goal; its basic use is instrumental in the achievement of one's goals or aims. This paper is part of a descriptive analysis section from a study conducted on organizational power and leadership. The researcher gathered insights into the lived experiences of like-minded sample of respondents as they described organizational power politics and how they view and use power in their various leadership positions ${ }^{1}$.
\end{abstract}

Keywords: power, bases of power, organizational leadership, power and leadership, organizational power politics

\section{Introduction}

The study of power as part of organizational political action by all stakeholders is an emerging field of interest aimed at improving individual leadership and organizational effectiveness. The definition of power is a person’s capacity to persuade another person to do something (Adler, du Gay, Morgan, \& Reed, 2014). Income, social class, political influence, and property can determine a person's ability to hold a position of power in the society. All participants within a group possess power. They use power regardless of organization type, gender, rank, and social class (Mastenbroek, 2005). Men and women emphasize different ways to manipulate power, as do subordinates when compared to superiors and peers. The political dynamics of groups becomes dependent on the presence of power and its use (Fairholm, 2009).

German sociologist, Max Weber defined power as the probability that one actor within a social relationship will be in a position to carry out his own will despite resistance. Along similar lines, Emerson suggests that "The power of actor A over actor B is the amount of resistance on the part of B which can be potentially overcome by A". Power appears to involve one person changing the behavior of one or more other individuals-particularly if that behavior would not have taken place otherwise. (Cucciolla, 2017, pp. 33-34)

There are several reasons to obtain power, including the following: (a) to achieve a goal; (b) to reward

Remi Alapo, doctor of management (DM), Organizational Management and Leadership, University of Phoenix, Phoenix, Arizona, USA.

Correspondence concerning this article should be addressed to Dr. Remi Alapo, Social Sciences Dept., Room No. 671, Borough of Manhattan Community College, NY 10007, USA.

1 The following is a revised section on organizational power and leadership, a part of the dissertation research by Alapo, R. (2011). The Role of Culture on the Leadership Styles of Generation X Women in Nigeria: A phenomenological Study. School of Advanced Studies, University of Phoenix, Arizona. 
supporters or followers; (c) to deter opponents; (d) to coerce subordinates into performing certain actions; (e) to gain expert knowledge; and (f) to gain ideas over others (McShane \& Travaglione, 2003). Throughout history, the theory of power has been depicted in various organizational settings, nobles, or elites having more power in society over commoners and those with less wealth, men holding certain positions over women, and so on. The works of Karl Marx describes how those with money have certain influences over those who do not have money or wealth (Christian, 2009).

Three theoretical perspectives were used as measuring guidelines: Marx's Theory of Capitalism, the Elite theories, and Pluralist theories. The works of Karl Marx in the 19th century and Max Weber in the 20th century showed that Elitist theories, such as social class and economic structure, sometimes determine the ways in which leaders use power. According to pluralist theories, group members' success is dependent on the appropriateness of power tactics, along with the political dynamics he or she employs with other people in a group. Marxists theories of power state that a person can hold power as a result of economic and political influence in the society, not necessarily because the person holds an elected office or holds positions of power within an organization (Clegg \& Haugaard, 2012).

\section{Background of Study}

Organizational power politics permeates all actions within an organization. Power is one person's ability to exert change on another person's way of life and actions (Sweeney \& McFarlin, 2002). Using power is a valuable means to influence and achieve intended desires and future action in others. Power is instrumental; it's a means to achieve goals other than the attainment of power itself. Power may also be expressed as one person's dependence on another. Power can, and sometimes is, a goal; its basic use is instrumental in the achievement of one's goals or aims.

Power has utility for the group member most often as an intermediary tool to achieve some personal desired end value (Victor \& Turner, 2006). Sources of power include: legitimate reasons for achieving a goal, to reward supporters or followers, to deter opponents, to coerce subordinates into performing certain actions, to have expert knowledge, and ideas over others (McShane \& Travaglione, 2003). Some see power as manipulation, coercion, control, reward, force, or an approach to leadership. Employees who are coerced often have more on-the-job dissatisfaction, lacking commitment to the organization, and experience withdrawal from both the goals of their job and the organization. Organizations attempting to streamline their operations for maximum efficiency may implement a coercive power method overall, coercing employees leads to a decline in their ability to be productive, which often affects the bottom line of organizations (Victor \& Turner, 2006).

\section{Bases of Power}

Power in an organizational setting can sustain goals and lead to central authority among subordinates, followers, or peers. Power can prove discretion on an organization's progress or culture; it can also increase the value and visibility of a leader within and outside of the organizational setting (McShane \& Travaglione, 2003). Four factors serve best to determine behavior within afirm: personalities, stage of organizational development, scarce resources, and ambiguous circumstances. These four factors also dictate group politics (Mastenbroek, 2005).

The consequences of a leader with power in an organizational setting can mean commitment, approval, compliance, or resistance from others and the ability of a leader to exercise good leadership within the organization (Noll, 2001). The use of power can also mean explicit or implicit behaviors that are assigned to an 
individual or prohibited to lead others in leadership positions (Karkoulian \& Osman, 2006). A leader's capacity to handle and manipulate the different forms of power will directly have effects on his or her leadership in an organization (White, 2010). According to social psychologists French and Raven, in 1959 their work on the bases of social power identified the following five sources of power: coercive, reward, legitimate, expert, and referent. In their research study, they defined the social theory of power as follows:

The strength of power of $\mathrm{O} / \mathrm{P}$ in some system a is defined by the maximum potential of $\mathrm{O}$ to influence $\mathrm{P}$ in a...it is assumed that $\mathrm{O}$ is capable of various acts which, because of some more or less enduring relation to $\mathrm{P}$, are able to exert influence on P. O's power is measured by his maximum possible influence, though he may choose to exert less than his full power. (1) reward power, based on P's perception that $\mathrm{O}$ has the ability to mediate rewards for him; (2) coercive power, based on P's perception that $\mathrm{O}$ has the ability to mediate punishments for him; (3) legitimate power, based on the perception by $\mathrm{P}$ that $\mathrm{O}$ has a legitimate right to prescribe behavior for him; (4) referent power, based on P's identification with $\mathrm{O}$ (and);

(5) expert power, based on the perception that $\mathrm{O}$ has some special knowledge or expertness. (pp. 156-157)

\section{Reward Power}

It is a positive power that refers to the ability to get work done through others on the basis of one's power to grant rewards. Such rewards could be either tangible or intangible rewards. For example, a leader or manager can reward employees with monetary, flexible schedule, and job promotion.

\section{Legitimate Power}

It depends on organizational position and authority. It refers to the power conferred by a person's organizational position. This type of power is based on the premise that an organizational leader has the authority and the right to give orders based on their position within the organization. This type of power is based on the hierarchy that a leader holds in an organization and while employees may comply to legitimate power based on the authority or role of a leader or manager, it does not mean that they will be cooperative in an organization setting or commit to organizational goals (Victor \& Turner, 2006).

\section{Expert Power}

It derives from a person's expertise or specialized knowledge of a certain subject perceived as important to the organization. A manager may hold more knowledge or skills than their subordinates with additional skills training or years of experience on the job. A person may specialize in a specific task within an organization who does not possess the same knowledge or skill. They become "experts" in the knowledge they possess over others and not necessarily because they are superior in class to others within the same organizational structure.

\section{Referent Power}

It is when people identify with an individual and attempt to emulate that individual's behavior. The person who acts as a model for reference has power over the person who emulates his behavior, such as in a transformational leadership approach where a leader can move along their subordinates with a charismatic behavior.

\section{Coercive power}

Organizations attempting to streamline their operations for maximum efficiency may implement a coercive power method. Employees who are often coerced have more on-the-job dissatisfaction, lack commitment to the organization, and experience withdrawal from their job’s and organization's goals. Coercing employees leads to a decline in their ability to be productive, a fact that often affects the bottom line of organizations. 


\section{Methodology}

The research group involved an organization, body of members, characterized by unique culture, values, and social beliefs. The scope of this research study was practical orientation to examine applied power as used by individuals. A phenomenological qualitative research study explored the leadership experiences and the preferred power politics on the view and use of power within an organization. The research was conducted amongst a group of 50 women, aging from 35 to 50 years in leadership positions in an organization working to increase the number of women in management and leadership positions in Nigeria. An open-ended questionnaire was appropriate for the proposed research study because it allowed participants to describe their day-to-day lived experiences. The researcher gathered insights into the lived experiences of like-minded sample of respondents from the research population as they described their organizational power politics and leadership experiences on the view of power within their organizations. The following is the descriptive analysis of the section on power and organizational leadership.

\section{Results}

\section{Descriptive Summary 1:}

As someone in leadership position, what are your views and perspective on power?

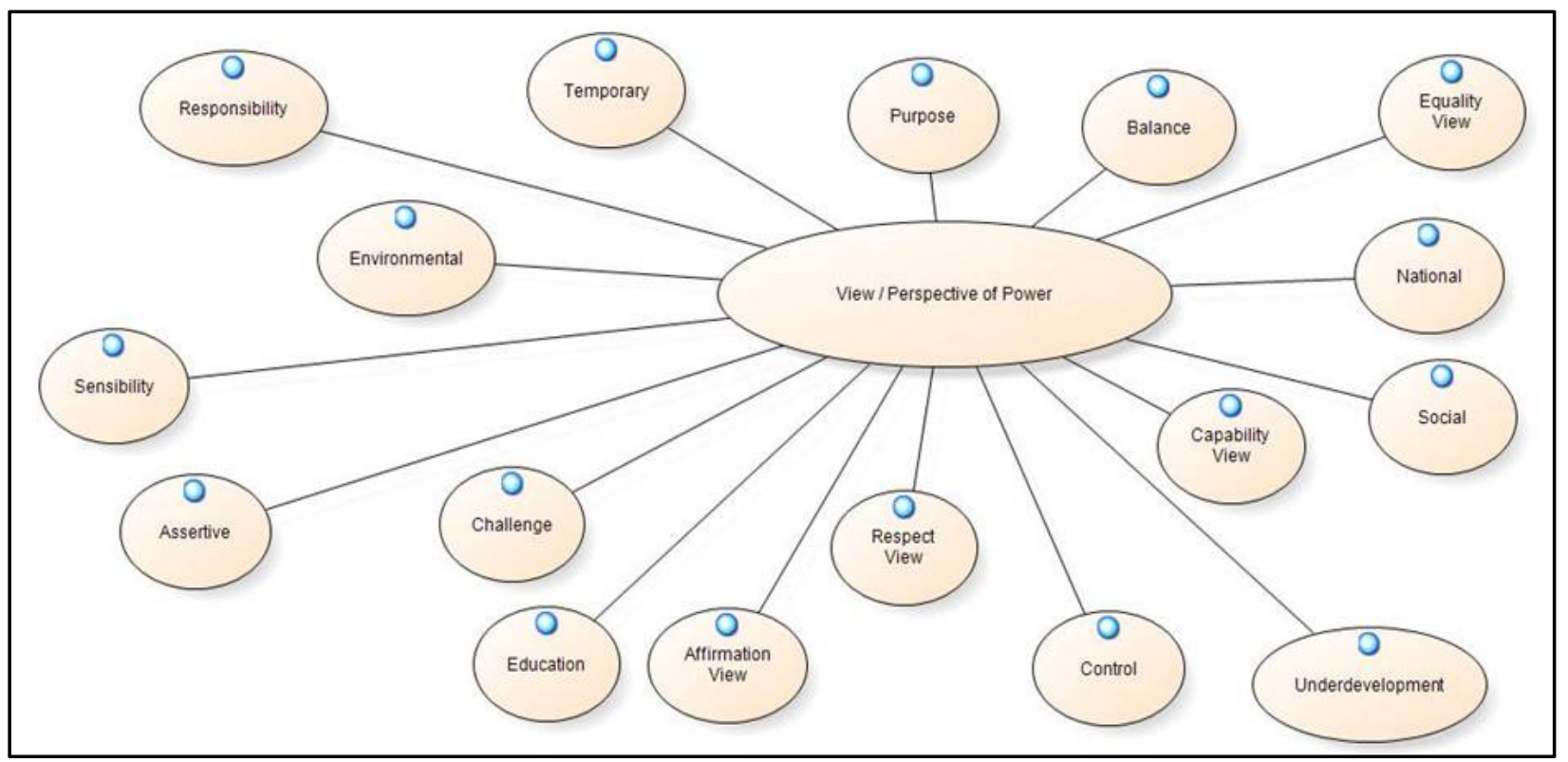

When asked what the view of power was as a woman in position of power, the responses that emerged were the ability to openly display power based on certain cultural factors and depending on the environment or region. Some of the participants responded that their views and perspectives meant: the approval of others about the leader's knowledge, skills, recognition, personal conviction, and going the extra mile to be taken seriously. While some said that understanding the environment and political landscape at work, using their knowledge base in managing expectations, and communicating effectively meant power. Power to some meant responsibility, integrity, the ability to control, act, and lead positively, the opportunity to lead, make rules, and punish rightly within the organization were some of the answers that emerged on the meaning and usage of power. 


\section{Descriptive Summary 2:}

What in your opinion do you consider as an asset on the use of power within your organization?

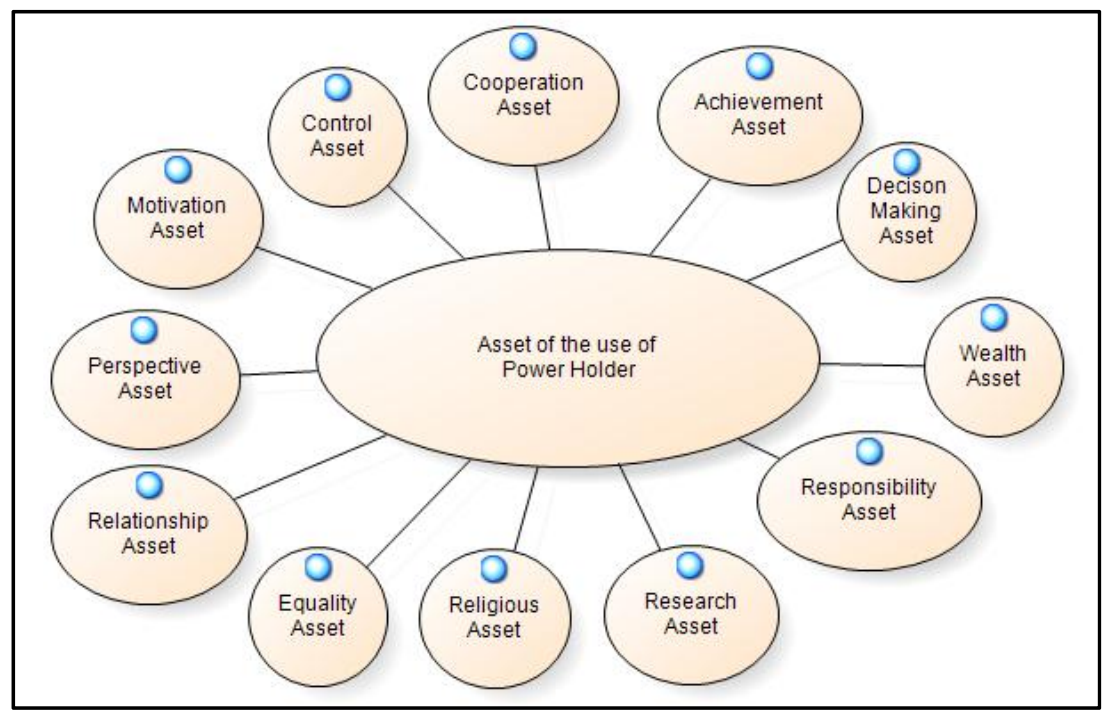

When asked to describe an asset of power, some of the responses derived from the answer were that power is viewed as an achievement which allows discipline, control, reliability, the ability to achieve results and to get the job done. Power asset allows for participants to showcase their talents, skills, professionalism, hard work, and dedication. The ability to take responsibility, build trust, relationships with supervisors and subordinates, command respect is an asset of power to many because it brings cooperation and supports as well as the opportunity to motivate subordinates for staff development and makes a difference in the life of others in the society, as a role model. Power as an asset allows for clearer goals to be achieved through well thought decision making processes and active listening. This enables some of the participants to establish vision and long-term goals, problem solve, have self-confidence and in-depth knowledge of business and organizational environment and the ability to generate returns for stakeholders.

\section{Descriptive Summary 3:}

\section{What in your opinionis your description on the effects of your demographics on your usage of power?}

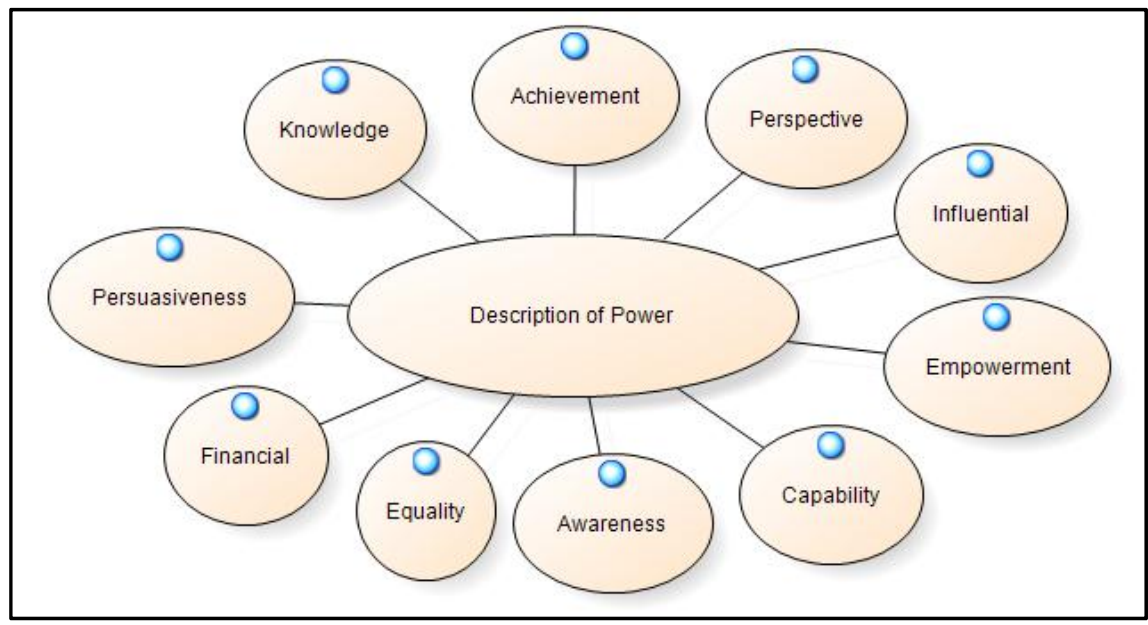


When asked on the role of participant's demographics, and its effects on their view of power, many answered that their educational, economic, and religious backgrounds have had a positive effect on their leadership style and view of power. One respondent answered that their present demographics has given them the power to realize that they can achieve whatever they set their mind to achieve so long as they stay hardworking, honest, and trustworthy. While another responded that in a lot of ways, their "religious and economic background has kept them humble and not to abuse power". All respondents were from the Christian faith and belonged to the middle- and upper-class families.

Economically several of the respondents answered that it has given them more confidence and power to be able to afford courses and trainings on leadership. Another responded coming from a relatively humble background economically, they have witnessed the amount of regard power bestows on a person. Another participant responded:

The level of power a person wields determines where he or she speaks, and who listens to them. It determines those who seek to do business with them, and the amount of contribution and effect they can have on their community.

All these factors shape and influence their view of power. Another respondent said that their economic background makes it comfortable to perform their leadership role without fear or favor, knowing that if they lost their jobs for challenging a superior, they will not starve or die of poverty. Economic background has enabled many of the participants to give back to society and motivated them to encourage subordinates to achieve economic independence.

One respondent answered that their education has given them the power they needed to know and understand business from all aspects of the books. Another participant responded that they feel the path that they have chosen in their level of education paved a good career for them and that they were able to get better opportunities because not many women in the respondent's ethnic and age group have this opportunity they responded. One respondent mentioned that education has impacted their view of power positively as they are able to impact the lives of many people who perceive them as a role model and aspire to get education. While another respondent answered that their educational experience exposed them to different styles of leadership that they would not have considered as a woman due to their cultural background, but have felt empowered to utilize.

\section{Conclusion}

Organizational power politics permeates all actions within an organization. Power is one person's ability to exert change on another person's way of life and actions. Using power is a valuable means to influence and achieve intended desires and future action in others. Power is instrumental; it's a means to achieve goals other than the attainment of power itself. The consequences of a leader with power in an organizational setting can mean commitment, approval, compliance, or resistance from others and the ability of a leader to exercise good leadership within the organization (Noll, 2001). The use of power can also mean explicit or implicit behaviors that are assigned to an individual or prohibited to lead others in leadership positions (Sweeney \& McFarlin, 2002). A leader's capacity to handle and manipulate the different forms of power will directly have effects on his or her leadership in an organization. From the study, this descriptive analysis from the research section on power is that the view, meaning and use of power emerged as the ability to openly display power based on certain environmental and organizational. 


\section{References}

Adler, P. S., du Gay, P., Morgan, G., \& Reed, M. (2014). Oxford handbook of sociology, social theory and organization studies. Oxford, England: Oxford University Press.

Christian, M. (2009). Assessing class: Wealth. Stratification and class in the US. EBSCO research starters.

Clegg, S., \& Haugaard, M. (2012). Power and organizations. Thousand Oaks, CA: Sage.

Cucciolla, R. M. (Mar., 2017). State and political discourse in Russia. Reset-Dialogues on Civilizations. Rome, Italy.

Fairholm, G. W. (2009). Organizational power politics: Tactics in organizational leadership (2nd ed.). Santa Barbara, CA: ABC-CLIO, Incorporated.

French, J. R. P., \& Raven, B. (1959). The bases of social power. In D. Cartwright (Ed.), Studies of social power (pp. 150-167). Ann Arbor, MI: University of Michigan, Institute for Social Research.

Karkoulian, S., \& Osman, Y. (Oct., 2006). The effect of French and Raven power on knowledge acquisition, knowledge creation and knowledge sharing: An empirical investigation in Lebanese organizations. 6th Global Conference on Business \& Economics. Gutman Conference Center, USA.

Mastenbroek, W. F. G. (Jan., 2005). Emotion management, status competition, and power play. Organizational behavior in historical perspective.

McShane, \& Travaglione. (2003). Organisational behaviour on the Pacific Rim. McGraw-Hill Australia Pty Ltd.

Noll, C. L. (2001). Management: Authority and responsibility. Encyclopedia of Business and Finance, (2). New York: Macmillan Reference, USA.

Sweeney, P. D., \& McFarlin, D. B. (2002). Power and influence: Exercising leadership and practicing politics. Organizational behavior: solutions for management. McGraw-Hill, Higher Education.

Victor, D. A., \& Turner, M. C. (2006). Leadership styles and bases of power. In M. H. Marilyn (Ed.), Encyclopedia of management (5th ed., pp. 442-445). Detroit: Gale.

White, S. (March 04, 2010). Leadership, power, and politics: How can you obtain the power to shape action in your organization? San Francisco, CA: Ms. J. D. 